See discussions, stats, and author profiles for this publication at: https://www.researchgate.net/publication/322663706

\title{
Biomaterials for revascularization and immunomodulation after spinal cord injury
}

Article in Biomedical Materials · January 2018

Dol: 10.1088/1748-605x/aaa9d8

\section{CITATIONS}

3 authors, including:

Agnes Haggerty

University of Miami Miller School of Medicine

7 PUBLICATIONS 84 CITATIONS

SEE PROFILE
READS

65

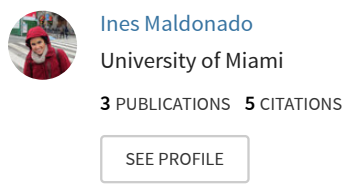

Some of the authors of this publication are also working on these related projects:

Project Synergy between mesenchymal stem cells and macrophages for spinal cord repair. View project 
PAPER

Biomaterials for revascularization and immunomodulation after spinal cord injury

To cite this article: Agnes E Haggerty et al 2018 Biomed. Mater. 13044105

View the article online for updates and enhancements.
Related content

- Physics of Cancer: Inflammation and
$\frac{\text { cancer }}{\text { C T Mierke }}$
- Physics of Cancer: The mechanical and
structural properties of the
microenvironment
C T Mierke
- From de novo peptides to native proteins:
advancements in biomaterial scaffolds for
acute ischemic stroke repair
James D Tang and Kyle J Lampe




\title{
Biomedical Materials
}

\section{PAPER}

CrossMark

\section{Biomaterials for revascularization and immunomodulation after spinal cord injury}

RECEIVED

REVISED

2 January 2018

ACCEPTED FOR PUBLICATION

23 January 2018

Agnes E Haggerty ${ }^{1,6,7}$, Inés Maldonado-Lasunción ${ }^{1,2}$ and Martin Oudega ${ }^{1,3,4,5,6,7}$

PUBLISHED

25 April 2018

1 The Miami Project to Cure Paralysis, University of Miami Miller School of Medicine, Miami, FL, United States of America

2 Department of Regeneration of Sensorimotor Systems, Netherlands Institute for Neuroscience, Institute of the Royal Netherlands Academy of Arts and Sciences, Amsterdam, The Netherlands

3 Department of Neurological Surgery, University of Miami Miller School of Medicine, Miami, FL, United States of America

4 Bruce W Carter Department of Veterans Affairs Medical Center, Miami, FL, United States of America

Affiliated Cancer Hospital \& Institute of Guangzhou Medical University, Guangzhou, People’s Republic of China

Authors to whom any correspondence should be addressed.

7 Address for correspondence: University of Miami Miller School of Medicine, The Miami Project to Cure Paralysis, 1095 NW 14th Terrace (R-48), Miami, FL 33136-1060, United States of America.

E-mail: aeh92@med.miami.edu and moudega@miami.edu

Keywords: spinal cord injury, blood vessels, blood-spinal cord barrier, vascularization, angiogenesis, inflammation, bioengineering

\begin{abstract}
Spinal cord injury (SCI) causes immediate damage to the nervous tissue accompanied by loss of motor and sensory function. The limited self-repair competence of injured nervous tissue underscores the need for reparative interventions to recover function after SCI. The vasculature of the spinal cord plays a crucial role in SCI and repair. Ruptured and sheared blood vessels in the injury epicenter and blood vessels with a breached blood-spinal cord barrier (BSCB) in the surrounding tissue cause bleeding and inflammation, which contribute to the overall tissue damage. The insufficient formation of new functional vasculature in and near the injury impedes endogenous tissue repair and limits the prospect of repair approaches. Limiting the loss of blood vessels, stabilizing the BSCB, and promoting the formation of new blood vessels are therapeutic targets for spinal cord repair. Inflammation is an integral part of injury-mediated vascular damage, which has deleterious and reparative consequences. Inflammation and the formation of new blood vessels are intricately interwoven. Biomaterials can be effectively used for promoting and guiding blood vessel formation or modulating the inflammatory response after SCI, thereby governing the extent of damage and the success of reparative interventions. This review deals with the vasculature after SCI, the reciprocal interactions between inflammation and blood vessel formation, and the potential of biomaterials to support revascularization and immunomodulation in damaged spinal cord nervous tissue.
\end{abstract}

\section{Introduction}

The involvement of the vasculature in spinal cord injury (SCI) and its anatomical and functional consequences are unambiguously evident [1-5]. In the healthy spinal cord, blood vessels provide oxygen and nutrients and remove metabolic waste, which are crucial functions for the maintenance and activity of neural cells and their intricate interactions within the nervous tissue. Trauma to the spinal cord destroys blood vessels in the injury epicenter and breaches the blood-spinal cord barrier (BSCB) of blood vessels in the surrounding tissue (i.e., penumbra) causing bleedings, inflammation, and edema which significantly contribute to secondary loss of neural cells, extracellular matrix (ECM), and tissue integrity [6, 7]. The initial and secondary injury together determine the extent of motor and sensory function impairments after SCI. Recently, pericytes were associated with impaired blood flow and motor function in chronic SCI [8]. An endogenous generation of new blood vessels (i.e., angiogenesis) occurs at the site of injury as part of an effort of self-repair, but many of these new blood vessels fail to organize into a functional vasculature; recovery due to self-repair is limited. In cases where recovery of function is observed after SCI, it is typically due to plasticity within the spinal cord rather than repair of the damaged tissue. 
A

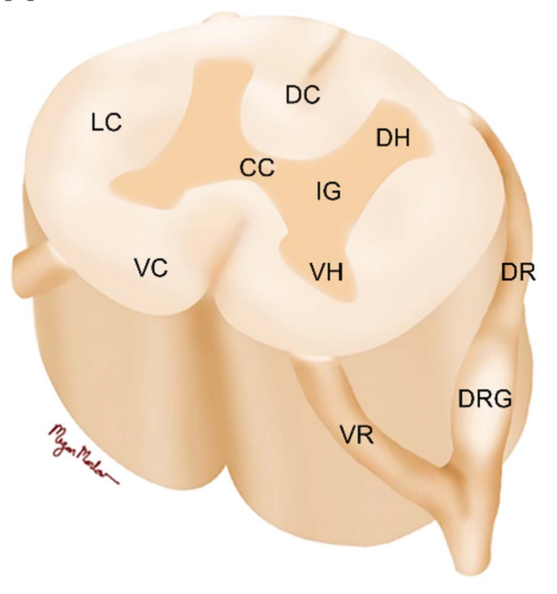

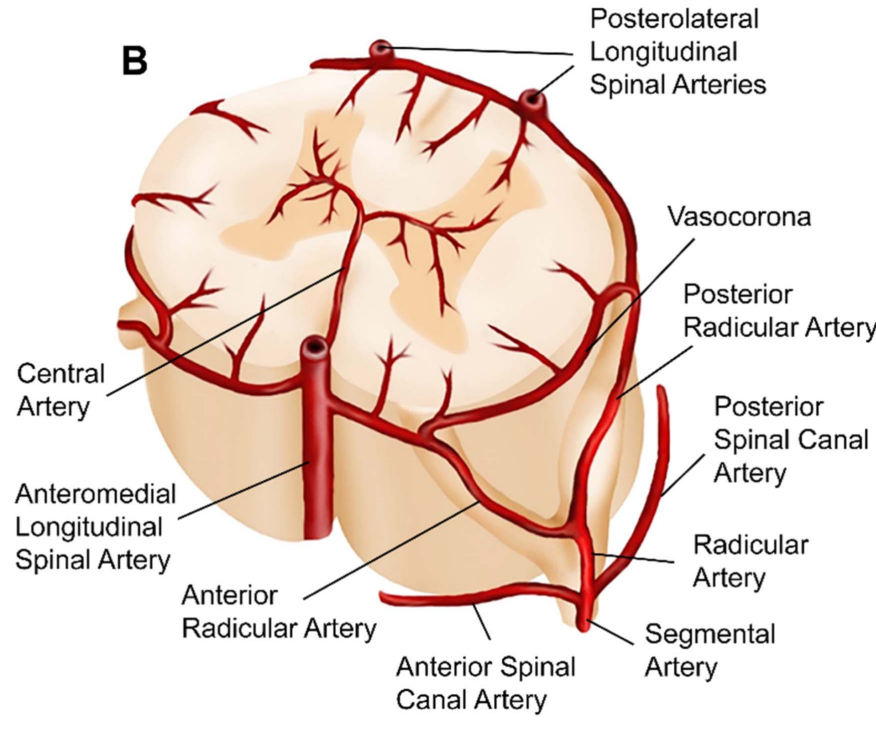

Figure 1. Schematic representations of the spinal cord showing (A) the general anatomy and (B) the fully developed vasculature. Abbreviations: CC, central canal; DC, dorsal column; DH, dorsal horn; DR, dorsal root; DRG, dorsal root ganglion; IG, intermediate gray; LC, lateral column; VC, ventral column, VH, ventral horn; VR, ventral root.

SCI-induced vascular damage exacerbates inflammation of the damaged nervous tissue. The regulated infiltration of immune cells, including neutrophils, lymphocytes, and macrophages, together with those that inundate the site because of disrupted blood vessels contribute to the overall damage. However, inflammation can also mediate reparative effects after SCI. Immune cells can differentially influence angiogenesis according to the predominant macrophage phenotype, aiding the reestablishment of functional vasculature and tissue repair.

Because of their key roles in SCI and repair, the vasculature and inflammatory response constitute potential therapeutic targets. Approaches to limit the loss and/or malfunctioning of blood vessels, promote and guide angiogenesis towards new functional vasculature, and shift the inflammatory response from cytotoxic to reparative could all curb secondary loss of neural cells/tissue and, thus, support functional recovery [5]. Moreover, new functional vasculature and immunomodulation may enhance the outcome of approaches that employ drugs or cells to elicit repair and recovery. There is a potential role for bioengineered materials in limiting the loss and/or mediating the formation of blood vessels or modulating the inflammatory response in the injured spinal cord. The fast expanding knowledge of molecules involved in angioprotection and angiogenesis, and in the functioning of blood vessels [9-11], as well as in immunomodulation serves as a molecular foundation for tailored engineering of materials with therapeutic value for the injured spinal cord.

Here, we will review and discuss revascularization, inflammation, and the relationship between these events, after SCI. We will examine the potential of engineered and natural biomaterials to promote and guide revascularization and immunomodulation in support of spinal cord repair. Also, we will discuss how insights from other fields, such as cancer, muscle ischemia, and chronic wounds, can support the development of therapies for angiogenesis and immunomodulation after SCI.

\section{Spinal cord anatomy and vasculature}

The anatomy of the spinal cord (figure 1(A)) reflects its function as an intermediate between the brain and the periphery to gait and modulate information in both directions. The vasculature of the spinal cord is organized such that its ventral aspect is supplied centrifugally by the central artery and the anterior part of the vasocorona (i.e., a vascular net on the pia mater) while its dorsal aspect is supplied centripetally by the posterolateral longitudinal spinal arteries and the posterior part of the vasocorona (figure 1(B)). The supply to the central aspect of the spinal cord (known as the watershed zone) depends on overlapping terminal vascular fields. The capillary bed density is higher in the gray matter than in the white matter $[12,13]$, likely to meet the greater demand for oxygen and nutrients by the many metabolic highly active neural cells.

\section{SCI and consequences for the vasculature}

The predominant mechanism of SCI in humans is a contusion which causes immediate neural cell death and severance and/or demyelination of passing axons $[6,7]$. The loss of cells/tissue is progressive due to secondary pathophysiological events [14, 15]. SCI typically causes loss of the ability to move legs, with 


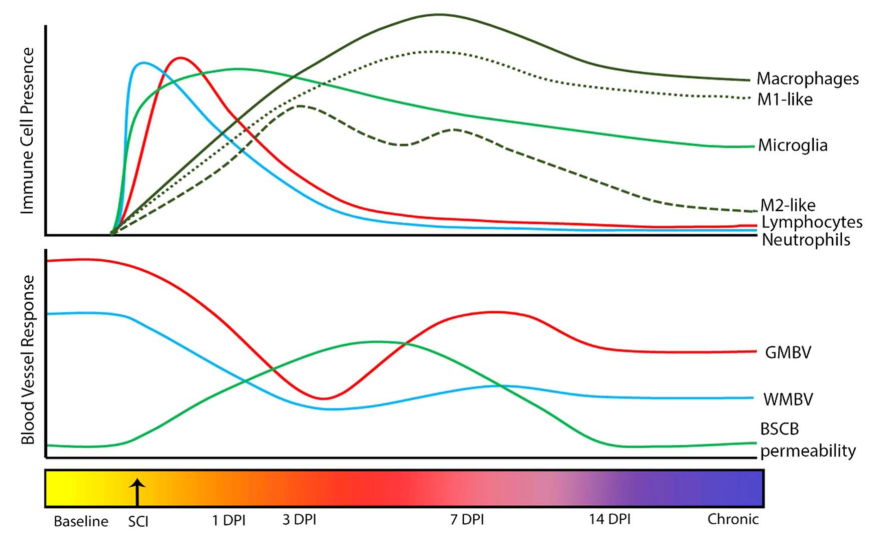

Figure 2. Schematic of relative changes in immune cell presence (top) and BSCB permeability and blood vessel presence (bottom) after SCI. GMBV = gray matter blood vessels, WMBV = white matter blood vessels, BSCB = blood spinal cord barrier. Based on data from [35, 36, 43-47].

thoracic or lumbar SCI, or arms and legs, with cervical SCI, as well as sensory, autonomic, bladder, bowel, and sexual dysfunction, which all impact the quality of life $[3,16]$.

Mechanical forces during SCI result in destruction and shearing of blood vessels causing hemorrhages [15]. In blood vessels nearby, endothelial cells (ECs) may start to degenerate in minutes after an insult and die over the following days thereby further increasing vascular damage [17-19]. Additional ECs may die due to oxidative stress, mediated by reactive oxygen species [20], and anoikis, mediated by detachment from ECM [21]. Vasculature is also affected by breached BSCB in blood vessels within the penumbra due to shear stress during the insult, resulting in hyperpermeability of the blood vessels [15]. Relative changes in BSCB permeability and blood vessel presence after SCI are depicted in figure 2 .

\section{Vascular damage contributes to the consequences of SCI}

After SCI, petechial bleedings are present throughout the injury epicenter. The presence of blood cells, as well as immune/inflammatory cells, contributes directly and indirectly to additional loss of nervous tissue [3, 22]. Vascular damage results in an abrupt loss of hemostasis and, eventually, an ischemic cascade, i.e., the accumulation of cytotoxic proteolytic enzymes and reactive oxygen species, which causes additional cell death and tissue loss [23]. The lack of oxygen causes irreversible damage within minutes after injury. A breached BSCB in blood vessels of the penumbra contributes to further loss of cells/tissue by adding to bleeding and inflammation. Blood vessels with a malfunctioning BSCB also further disrupt the fluid homeostasis resulting in accumulation of interstitial fluids and edema (swelling). In chronic SCI, pericytes contribute to hypoxic conditions in the spinal cord nervous tissue caudal to an injury and impaired motor function through the constriction of local capillaries caused by pericytes-derived trace amines [8].

There are also systemic consequences due to vasculature damage after SCI. An injury to the spinal cord affects autoregulation causing reduced blood flow and, as a consequence, ischemia, which in turn leads to loss of initially spared tissue $[16,23]$. Imbalances in nitric oxide (NO) may influence arteriolar tone in the injured spinal cord [24]. SCI can also cause neurogenic shock [14], bradycardia, and hypotension which all affect blood supply to the spinal cord and thus contribute to the overall damage. These consequences also have indirect effects on organs [25] because the reduced arterial blood pressure may cause a reduction in microvascular blood flow and, as a result, organ dysfunction.

\section{Inflammation after SCI-interactions with the vasculature}

\subsection{Vascular dynamics and inflammation after injury}

Vascular damage and inflammatory events after SCI are tightly intertwined (figure 2). The acute immune response is initiated by signals released by damaged and apoptotic cells [26, 27] and exacerbated by circulatory spills from the damaged vasculature [28]. The early phase of the acute immune response is characterized by inflammation, in which immune cells such as neutrophils, lymphocytes, and macrophages are involved in the removal of cellular debris, which causes cytotoxicity. During this early phase, the immune cell infiltration, with damaged blood vessels as a port of entry, is sequentially regulated by chemokines from damaged cells [29]. Neutrophilattracting chemokines recruit neutrophils within the first $6 \mathrm{~h}$ after injury, interferon- $\gamma$-inducible protein 10 (IP-10) mediates the infiltration of lymphocytes at 6-12 h after injury, and macrophage chemoattractant protein 1 (MCP1) recruits macrophages at $12-24 \mathrm{~h}$ 
after injury [30-32]. The presence of immune cells in time after SCI is depicted in figure 2. Microglia, the local immune cells in the spinal cord, are activated within minutes after injury to become the inflammatory tissue-resident macrophages [33]. The later phase of the acute immune response refers to the decrease in inflammatory cells and cytokines like neutrophils, interferon-gamma (IFN- $\gamma$ ) or tumor necrosis factor alpha (TNF- $\alpha$ ) [29, 34], along with the shift of inflammatory macrophages (M1-like) to reparative phenotypes (M2-like) [35, 36]. In normally regenerating tissues, the acute immune response resolves into wound healing and absence of immune cells. After SCI, the permanent presence of inflammatory macrophages is considered a chronic immune response [37].

Activated immune cells within the injury site secrete enzymes, such as elastase [38], that alter the basement membrane of blood vessels, increasing their permeability and, thus, the infiltration of inflammatory cells, including macrophages [38, 39]. Once recruited, macrophages secrete matrix metalloproteinases that mediate ECM remodeling to activate an angiogenic response [40, 41]. Thus, the enhanced inflammation after SCI caused by the disrupted vasculature may exacerbate the overall tissue damage and extend the injury; however, it also plays an important role in eliciting effects beneficial for repair [39, 42].

\subsection{Macrophages}

The infiltrated and tissue-resident macrophages have the most influence on tissue inflammation, resolution, and repair, due to their rich secretome and phenotypic plasticity (reviewed in [39, 48]; also [42, 49-52]. Macrophages respond to their biochemical microenvironment adopting different activation states. The different phenotypes are characterized by surface marker expression, cytokine secretion and/or phagocytic behavior. Activated macrophages undergo a stimulus-dependent phenotypical polarization ranging between an inflammatory, cytotoxic functional state (M1-like), and a reparative, regulatory (M2-like) functional state $[35,53,54]$. In regenerating tissues, the macrophage population progressively shifts from an inflammatory to an anti-inflammatory and reparative phenotype [36, 39]. In non-regenerating tissues, such as the spinal cord nervous tissue, this shift does not occur effectively and inflammation does not resolve, resulting in a chronically cytotoxic state that limits repair [29, 36, 37].

The M1-like and M2-like macrophages are both important for the formation of blood vessels, albeit through vastly different actions and in a time-dependent manner. Contrary to their cytotoxic behavior, M1-like macrophages also secrete many pro-angiogenic molecules that initiate blood vessel sprouting and growth at the beginning of the angiogenic process $[40,55]$. M2-like macrophages secrete factors that attract pericytes and vascular smooth muscle cells to promote the maturation and stabilization of the newly formed vessels [39, 50, 56]. Moreover, the reparative M2-like macrophages secrete factors that contribute to the regulation of oligodendrocyte differentiation and remyelination [57] and support neuronal survival and outgrowth [35]. The functional characterization of macrophage phenotypes in wound healing, specifically after SCI, emphasizes the importance for the sequential regulation of angiogenesis and nervous tissue protection and remodeling.

Many studies suggest that modulating macrophage populations towards the M2-like phenotype may support repair [36, 39, 50, 58]. However, the action of M1-like macrophages is crucial for the breakdown of the existing ECM and the initiation of vascular growth. Promoting the shift to M2-like phenotype too early after injury could impede the angiogenic response and lead to excessive scar tissue and fibrosis [50, 59]. Thus, a time-controlled immunomodulation approach may be key for successful repair after SCI.

\section{Angiogenesis after SCI-interaction with inflammation}

Angiogenesis is necessary to re-vascularize regenerating tissue to provide nutrients, oxygen, and growth factors, remove metabolic waste, and serve as a gateway for immune cells [58]. Immune cells have a crucial role in regulating and promoting angiogenesis and this interaction is important for tissue regeneration $[29,48]$. Levels of colony stimulating factor 1 (CSF1) increase up to seven days after injury, which promotes infiltrating macrophage proliferation, differentiation, and migration. When CSF1 is inhibited or depleted, a decrease in vascular density and, consequently, a delay in wound healing can be found [41]. The importance of the macrophage phenotype in overall tissue repair was also shown by depleting these cells at different time points after injury which affected the extent of wound repair or scar formation [60].

Vascular endothelial growth factor (VEGF) and platelet-derived growth factor (PDGF) enhance angiogenesis in a sequential manner. Macrophages are partially responsible for the secretion of VEGF and PDGF, differentially over their phenotypic evolution during CNS wound healing [56, 61]. M1-like macrophages secrete VEGF and fibroblast growth factor (FGF2), which promote tip-endothelial cell fusion, protease secretion by them and other immune cells, and basal membrane remodeling to create tunnels for cell access [35, 40, 55, 62]. M2-like macrophages secrete PDGFBB and IGF-1 [63, 64], which attracts pericytes and vascular smooth muscle cells $[50,56]$. Interestingly, VEGF presents immunosuppressive potential in adult rats. Administration of VEGF to adult rats after T9 spinal cord transection reduces activation and proliferation of microglia [34]. The mechanisms 
regulating this process are not yet known, but it corresponds to the paired time line of angiogenesis and macrophage modulation to M2-like phenotypes.

The progressive transition in macrophage phenotype observed in regenerating tissues could be the key to a well-regulated angiogenesis, which is necessary for proper wound healing. Promoting appropriate immunomodulation after SCI while focusing on concomitant angiogenesis seems to be a promising strategy to accelerate SC repair.

\section{Angiogenesis as a therapeutic target}

Promoting angiogenesis after SCI constitutes a therapeutic strategy that may lead to reduced tissue damage and increased regeneration [61]. Knowledge about the molecular regulation of angiogenesis has been employed to promote angiogenesis for tissue regeneration or block angiogenesis for anti-cancer treatments $[65,66]$. After SCI, blood vessel breakdown and angiogenesis are dynamic and ongoing processes, that, if targeted within the first seven days post injury, could provide long-term benefits for recovery [44]. Once the acute injury period has passed, effectively targeting the angiogenic response for tissue regeneration and repair becomes much more challenging, for one, due to the progressive loss of tissue and vasculature. Consistent with this idea, the vast majority of studies described here which targeted angiogenesis and vascular remodeling have been tested in an acute injury model. The acute phase of SCI is defined by the breakdown of blood vessels and ongoing bleeding within the injury epicenter, paired with the leaking of blood vessels in the penumbra. Strategies to promote angiogenesis acutely after SCI showed reduced secondary degeneration and enhanced functional recovery [67-70]. Growth factor promoters of angiogenesis, such as VEGF isoforms and their receptors; Ang1 and Ang2; or FGFs, when administered to damaged tissue in animal models enhanced both angiogenesis and functional recovery [65]. Cells with paracrine angiogenic effects promoted revascularization when transplanted in SCI [71, 72]. Natural materials with pro-angiogenic properties or engineered materials to promote angiogenesis and/or to deliver pro-angiogenic molecules have also been tested and will be discussed in detail below.

In the sub-acutely injured spinal cord, the injury epicenter shows a prominent cavity with some additional loss of ineffectively formed blood vessels. Bleeding has stopped, and leakage in the penumbra has subsided. Little vascular dynamics occur between the acute and chronic SCI phase, but with time, there is a progressive loss of healthy vasculature at and around the injury site that eventually stabilizes in the chronic phase. Strategies to promote angiogenesis in the subacute and chronic injury phases are greatly lacking from the literature and one can imagine the therapeutic approach may be different from that taken during the acute injury phase. One study found that combining MSC transplants with a material functionalized for cell survival, led to improved revascularization and over ground walking in a chronic injury model [73]. Hopefully, with the advent of new and improved combinatorial strategies, additional successes will emerge for targeting angiogenesis in later phase SCI.

\section{Biomaterials for promoting angiogenesis after SCI}

Biomaterials can be utilized as a vehicle to deliver drugs or cells to promote angiogenesis in a controlled manner, potentially limiting dangerous side-effects from systemic and/or repeated delivery of these therapeutics such as tumor growth, rheumatoid arthritis, and retinal disease [74]. Some biomaterials possess innate angiogenic properties, while others can be functionalized or used as part of a combinatorial strategy to target angiogenesis. There is some discussion over the benefits of using degradable vs nondegradable materials. A biodegradable material can be used to deliver cells and factors for a predefined period of time and then be replaced by integrated host matrix. This alleviates concerns over long-term effects of the presence of a foreign material. However, breakdown products or sudden loss of structural stability may cause negative side effects. A non-degradable material could allow for structural stability for regenerating tissues without concerns for byproducts causing negative side-effects. However, long-term presence of a non-degradable material may elicit so far unknown side effects or, for example, if resection surgery is needed, loss of function. Taking these considerations into account, here we will discuss studies that have explored both degradable and non-degradable, natural and synthetic materials for their effects on angiogenesis after SCI.

\subsection{Natural biomaterials-ECM proteins}

ECM proteins are attractive options for use as angiogenic therapeutics after SCI because of their crucial role in embryonic blood vessel formation. Vitronectin, fibronectin, laminin, fibrinogen, collagen, osteopontin, among others, all bind $\alpha \mathrm{V} \beta 3$ integrin which is key in neovascularization [75]. Also, ECM proteins sequester and prolong the activity of growth factors, which could support the formation of blood vessels [76, 77]. Fibrin, hyaluronic acid (HA) and collagen are often explored for the promotion and/or facilitation of angiogenesis after SCI. Fibrin and HA are probably the most commonly used for proangiogenic effects on ECs and have shown promising results when tested alone [78] and in combination gels $[79,80]$. Fibrin has the ability to induce ECs to form capillary-like structures in vitro when used in 
three-dimensional culture systems [81, 82]. HA is associated with cell adhesion and migration [83, 84] and promoting angiogenesis [78]. Collagen inhibits EC tube formation when added to a fibrin matrix in vitro [82]. However, when combined with a collagen-binding VEGF peptide, significant improvements in vascularization accompanied by anatomical repair and functional recovery were observed in a model of a complete spinal cord transection [85]. Clearly, many ECM components can be employed to alter the angiogenic response after SCI. The specific requirements for a repair approach will dictate which ECM component is best to utilize.

In contrast to using a single ECM protein, some groups have championed combination hydrogels composed of de-cellularized ECM from a variety of sources including bladder, spinal cord, peripheral nerve, and brain [86-89]. These hydrogels contain a heterogeneous group of ECM proteins that may closely resemble the natural environment of ECs during angiogenesis. When an ECM-hydrogel was injected into a thoracic spinal cord hemi-section, significant increases in RECA-positive blood vessels were observed [89] and this result could be obtained with ECM hydrogels derived from a variety of tissue sources [89]. Similarly, increases in vessel density were found within an acellular sciatic nerve graft placed in the transected thoracic spinal cord [90].

\subsection{Synthetic biomaterials}

The advantage of using synthesized materials is that most are easily sterilized using standard methods and the mechanical properties, degradation characteristics, and release profile can all be optimized. Also, the chemical structure could be such that bioactive peptide groups can be linked chemically, functionalizing the material to enhance specific biological actions. For an angiogenic application, large pore sizes [91] and Arg-Gly-Asp (RGD) functionalized peptides [92] have been shown to improve vascularization. The most well-known and frequently explored synthetic biomaterials are poly (ethylene glycol) (PEG), poly (glycolic acid) (PGA), poly (L-lactic acid) (PLL), and the copolymer poly (lactic acid) (glycolic acid) (PLGA) (for review see [93]). These have been used extensively for drug and cell delivery into a variety of models of SCI. Also, the introduction of poly (2-hydroxymethacrylate) (PHEMA), matching the mechanical properties of spinal cord nervous tissue, in a hemisected cervical spinal cord resulted in significant blood vessel formation [94]. PHEMA hydrogels, however, do not degrade, which could positively or negatively affect their utility as a vehicle for drug delivery. Currently, the synthesis of modified and copolymer degradable alternatives is ongoing [95-97]. Attractive options for easy to manipulate synthetic hydrogels are thermoresponsive, water-based polyurethanes (PU) because these are liquid at room temperature and form a gel at $37^{\circ} \mathrm{C}$ without the need for adding any harsh chemical cross linkers [98-100]. In addition to the favorable physical properties, $\mathrm{PU}$ is associated with enhanced revascularization after implantation [101]. An overview of pro-angiogenic natural and synthetic biomaterials (used alone or modified as part of a combination strategy) can be found in table 1 .

\section{Materials for delivering angiogenic therapeutics}

Controlled release from a material injected into an injury is an attractive option to regulate the availability of angiogenic molecules necessary to govern the typically tightly controlled angiogenesis. Besides drugs, cells can also be introduced into an injury to promote angiogenesis directly through vessel formation and/or indirectly via secreted paracrine factors. Materials with specific degradation and release characteristics are required for proper drug or cell delivery into an injury in the spinal cord.

\subsection{Drug delivery for angiogenesis}

Biodegradable materials can be chosen or designed for specific release characteristics. Combining a biodegradable matrix with micro- or nano-spheres provides multiple mechanisms and points of control for drug delivery. The controlled delivery of angiogenic molecules to an injury is vital for regulating in a timely fashion the intricate process of establishing a new functional vasculature which requires many of the molecules involved to be present at specific times and in a specific sequence. During normal embryonic development, the availability of angiogenic molecules is tightly regulated to guarantee proper vascularization of tissue. After injury, revascularization is successful in some tissues but less so in the injured spinal cord, where new blood vessels are formed but fail to organize into a functional vasculature. Biomaterials can help to properly administer key molecules involved in angiogenesis to the damaged nervous tissue. Our expanding mechanistic knowledge of angiogenesis is of crucial importance to our efforts to design effective angiogenic strategies for spinal cord repair. Choosing materials with the appropriate degradation characteristics and sustained drug release properties following introduction into the damaged spinal cord may prove necessary for ideal outcomes. A summary of materials used for angiogenic factor delivery after SCI is provided in table 2 .

\subsection{Cell delivery for vascularization}

Several types of biomaterials have been used to facilitate and/or optimize transplantation of cells for spinal cord repair. Many cell types can provide continued trophic support and cytokine signaling to promote the formation of new vasculature. For instance, transplantation of mesenchymal stem cells 
Table 1. Overview of natural and synthetic materials with angiogenic properties, used alone or modified as part of a combination strategy

\begin{tabular}{|c|c|c|c|}
\hline Material & Endogenous role/rationale & Outcome & References \\
\hline \multicolumn{4}{|c|}{ Natural (ECM-based) materials } \\
\hline Fibrin & Wound healing & Angiogenesis & [102-104] \\
\hline FN & Cell adhesion & EC adhesion/activation, blood vessel formation & [105-108] \\
\hline $\mathrm{HA}$ & Cell proliferation and migration & Angiogenesis, inhibit glia scar formation & {$[78,80,83,109-111]$} \\
\hline Collagen & $\begin{array}{l}\text { Structural integrity and cell } \\
\text { adhesion }\end{array}$ & $\begin{array}{l}\text { Pro- or anti-angiogenic and pro- or anti- } \\
\text { inflammatory depending on crosslinking state } \\
\text { and combination with other factors/cells }\end{array}$ & {$[82,85,112]$} \\
\hline $\begin{array}{l}\text { De-cellularized } \\
\quad \text { tissues }\end{array}$ & $\begin{array}{l}\text { Contains all structures and signals } \\
\text { from ECM }\end{array}$ & Angiogenesis, anti-inflammatory & {$[89,90]$} \\
\hline \multicolumn{4}{|c|}{ Synthetic materials } \\
\hline PEG (600) & Biocompatible and biodegradable & $\begin{array}{l}\text { Angiogenesis, axon growth and repair in } \\
\text { chronic SCI }\end{array}$ & [113] \\
\hline PGA & Biocompatible and biodegradable & $\begin{array}{l}\text { Angiogenesis when combined with NSCs, not } \\
\text { apparent with either group alone }\end{array}$ & [114] \\
\hline PLL & Biocompatible and biodegradable & $\begin{array}{l}\text { Angiogenesis when mixed with HA and nogo-66 } \\
\text { function-blocking antibody, axon regrowth }\end{array}$ & {$[80]$} \\
\hline PLGA & $\begin{array}{l}\text { Biocompatible and biodegradable } \\
\text { with tunable mechanical } \\
\text { properties }\end{array}$ & $\begin{array}{l}\text { Angiogenesis when used as a transplant matrix for } \\
\text { NSCs and ECs }\end{array}$ & [115] \\
\hline PHEMA & $\begin{array}{l}\text { Biocompatible not degradable } \\
\text { unless modified }\end{array}$ & $\begin{array}{l}\text { Angiogenesis with modest inflammatory response } \\
\text { and minimal scarring }\end{array}$ & [94] \\
\hline PU & $\begin{array}{l}\text { Biocompatible and biodegradable; } \\
\text { thermo-responsive hydrogels }\end{array}$ & Angiogenesis & [101] \\
\hline
\end{tabular}

Abbreviations: $\mathrm{EC}=$ endothelial cell; NSC = neural stem cell; SCI = spinal cord injury; $\mathrm{ECM}=$ extracellular matrix; FN = fibronectin; $\mathrm{HA}=$ hyaluronic acid; PEG = poly(ethylene glycol); PGA = poly(glycolic acid); PLL/PLA = poly(L-lactic acid); PLGA = poly(lactic-coglycolic acid); PHEMA = poly(2-hydroxymethacrylate); PU = poly(urethane).

Table 2. Overview of materials used for delivery of angiogenic factors after spinal cord injury.

\begin{tabular}{|c|c|c|c|}
\hline Material & Factor & Outcome & References \\
\hline Fibrin & FGF & Angiogenesis, regeneration & [116] \\
\hline HA & FGF2; BDNF; VEGF & Angiogenesis, reduced inflammation & {$[117,118]$} \\
\hline Collagen & VEGF & Increased vasculature, functional recovery & {$[85]$} \\
\hline PLGA & $\begin{array}{l}\text { BDNF; NGF; NT3; FGF; VEGF; bFGF; } \\
\text { Ang-1 }\end{array}$ & $\begin{array}{l}\text { Increased vasculature, white matter sparing, } \\
\text { anti-inflammatory }\end{array}$ & [119-121] \\
\hline PDL & BDNF; FGF & Angiogenesis, regeneration & {$[116,122]$} \\
\hline GAM & $\begin{array}{l}\text { PDL-FGF2; PDL-BDNF; PDL-NT3; Col- } \\
\text { lagen-TSP-2 }\end{array}$ & $\begin{array}{l}\text { Increased neovasculature, neuron survival, } \\
\text { regeneration }\end{array}$ & {$[123,124]$} \\
\hline Alginate & bFGF; VEGF & $\begin{array}{l}\text { Angiogenesis, increase \# of endothelial cells/tubulin/ } \\
\text { GAP43 }\end{array}$ & [125-127] \\
\hline PEG & bFGF & Better delivery of bFGF & [128] \\
\hline $\begin{array}{l}\text { Acellular } \\
\text { spinal cord }\end{array}$ & PLGA-VEGF & Angiogenesis, sustained release & [119] \\
\hline
\end{tabular}

Abbreviations: FGF/FGF2/bFGF = fibroblast growth factor(2; bovine); BDNF = brain-derived neurotrophic factor; VEGF $=$ vascular endothelial growth factor; NGF = nerve growth factor; NT3 = neurotrophic factor 3; Ang-1 = angiopoietin-1; TSP-2 = thrombospondin2; $\mathrm{HA}=$ hyaluronic acid; PLGA = poly(lactic-co-glycolic acid); PDL = poly(D-lactic acid); GAM = gene-activated matrix; PEG = poly (ethylene glycol).

(MSCs) or their exosomes was found to result in the proliferation and migration of native ECs and the formation of new blood vessels [129, 130]. An alternative approach is to combine ECs with adiposederived stromal cells which provide pro-angiogenic factors for organizing the ECs into functional vasculature [131]. A summary of biomaterials used for angiogenesis-associated cell transplantation after SCI can be found in table 3 .

\subsection{Combination materials}

Biomaterials have shown great potential as critical components in multifaceted repair approaches. Their inherent therapeutic potential paired with tunable mechanical and degradation properties allows for combining materials such that their specific therapeutic effects can be optimized. Combination materials include hybrid materials, composed of different fused ECM proteins or moieties thereof, and combined 
Table 3. Overview of materials used for delivery of angiogenic factors after spinal cord injury.

\begin{tabular}{|c|c|c|c|}
\hline Material & Cell type & Outcome & References \\
\hline Fibrin & EC, MSC, ADSC, SC & $\begin{array}{l}\text { Neovascular formation (EC), Angiogenesis (MSC/ADSC) and stabilization } \\
\text { of vessels } \\
\text { No effect on vasculature with PDL/Fibrin/SC }\end{array}$ & {$[81,82,131-133]$} \\
\hline Collagen/gelatin & $\mathrm{EC}, \mathrm{MSC}$ & $\begin{array}{l}\text { Organized capillary network, Interrupted vascular formation, anti- } \\
\text { inflammatory, angiogenesis }\end{array}$ & {$[82,134,135]$} \\
\hline HA & $\mathrm{EC}, \mathrm{FB}, \mathrm{MSC}$ & Microvessel formation & [136] \\
\hline PEG & $\mathrm{NPC}+\mathrm{EC}$ & Angiogenesis & [115] \\
\hline
\end{tabular}

Abbreviations: $\mathrm{EC}=$ endothelial cell; $\mathrm{MSC}=$ mesenchymal stem cell; $\mathrm{ADSC}=$ adipose derived stem cell; SC = Schwann cell; $\mathrm{FB}=$ fibroblast; $\mathrm{HA}=$ hyaluronic acid; $\mathrm{PTFE}=$ polytetrafluoroethylene; $\mathrm{PLLA}=$ poly(l-lactic acid); PGA = poly(glycolic acid); PLGA = poly(co-lactic/glycolic acid); PEG = poly(ethylene glycol).

materials, consisting of a mix of natural and/or synthetic materials, matrices and microspheres, or bioactive materials that simultaneously deliver drugs or cells.

A combination of the salmon-derived ECM components, fibrin, laminin, and HA mixed into a hydrogel was shown to promote blood vessel formation when mixed with ECs in vitro and showed good biocompatibility with neural stem cells [79]. Importantly, the combination of these polymers resulted in better outcomes than each of the polymers individually [79]. A combination of synthetic PLGA microspheres loaded with pro-angiogenic factors and natural HA was shown to provide sustained drug-release, resulting in growth and stabilization of new blood vessels within the injury and improved anatomical and functional outcomes [118, 120].

Another type of combination material is one that concurrently delivers cells and growth factors. Transplanting MSCs genetically engineered to deliver VEGF within a matrix combined with PLGA microspheres with delayed release of the blood vessel stabilizing factor, Ang- 1 was found to result in mature, stable, blood vessels organized in a functional vasculature [120]. In another study, MSCs which are known to release a cocktail of pro-angiogenic factors, were combined with a three-dimensional gelatin scaffold surrounded by a PLGA sheath and implanted into the damaged spinal cord [135]. This combination of cells and materials was found to result in decreased inflammation and increased vascularization at the injury site and to support transplant survival [135]. These studies confirmed the potential of combination materials to exert multifaceted effects leading to repair.

\section{Materials for immunomodulation to support angiogenesis}

The tight association of angiogenesis with inflammation after SCI opens a therapeutic avenue for biomaterials with immunomodulatory actions to benefit the formation of new vasculature. Immunomodulatory biomaterials may contain native or engineered moieties that directly or indirectly modulate immune cells thereby promoting and/or guiding the generation of new blood vessels and a functional vasculature. After SCI, the predominant immune cell is the pro-inflammatory macrophage, of which the involvement in angiogenesis has been discussed above, and materials that can modulate the amount and phenotype of macrophages during different stages of injury may affect angiogenesis and repair.

\subsection{Material properties impacting the macrophage response}

The properties of materials determine their potential to affect the surrounding tissue. The stiffness of the material is a key determinant in its effect on the macrophage response [137]. It was shown that crosslinking an innocuous or mildly immunogenic material can initiate a stronger immune response from host tissue [138]. For instance, collagen in a non-crosslinked form elicits a mild immune response, while collagen in a crosslinked form evokes a much stronger immune response [139]. Also, when a collagen scaffold was combined with MSCs and introduced in a spinal cord hemisection, the macrophages were found to shift to M2-like phenotype [140]. Collagen scaffolds crosslinked with glutaraldehyde were shown to elicit a strong, but balanced M1-/M2-like macrophage response accompanied by increased vascularization of the scaffold [63], demonstrating the benefits of immunomodulatory materials. These studies using collagen scaffolds clearly emphasize the multiple therapeutic targets to consider when selecting a material to balance inflammatory and angiogenic responses for enhancing repair.

Residual cell parts can be an important factor in how a natural ECM-based material affects the immune response. It is critical that de-cellularized tissues used for implantation are analyzed for the presence of any cellular remains because these may evoke strong immune responses, unbalanced macrophage polarization to the M1-like phenotype, and increased scar deposition. On the other hand, properly de-cellularized scaffolds, i.e., free of any cellular residues, can promote the formation of new, functional, 
Table 4. Overview of materials with immunomodulatory effects after spinal cord injury.

\begin{tabular}{|c|c|c|c|}
\hline Material & Mechanism & Outcome & References \\
\hline Collagen & Integrin binding, stiffness & $\begin{array}{l}\text { Reduce immune response; M1-like to M2- } \\
\text { like shift }\end{array}$ & {$[63,139,140]$} \\
\hline Decellularizaed ECM & $\begin{array}{l}\text { Anti-inflammatory, pro-inflammatory if } \\
\text { contaminated by cellular components }\end{array}$ & $\begin{array}{l}\text { Anti-inflammatory, good tissue } \\
\text { integration }\end{array}$ & {$[141,149]$} \\
\hline Laminin (polylaminin) & Anti-inflammatory & Reduce macrophage infiltration & [150] \\
\hline Chitosan & Inhibit TNF- $\alpha$, IL-6, inhibit NF- $\kappa$ B via HSP-70 & Anti-inflammatory, anti-oxidative & [144-148] \\
\hline PLGA & $\begin{array}{l}\text { Improved survival and anti-inflammatory by } \\
\text { hMSCs }\end{array}$ & Anti-autoimmune; anti-inflammatory & {$[151]$} \\
\hline HA (High MW) & $\begin{array}{l}\text { Anti-inflammatory when stiffness-matched to } \\
\text { spinal cord }\end{array}$ & $\begin{array}{l}\text { Reduce macrophage infiltration; promote } \\
\text { M1-like to M2-like shift }\end{array}$ & {$[111,152,153]$} \\
\hline HAMC & Anti-inflammatory & $\begin{array}{l}\text { Reduce macrophage/microglia presence } \\
\text { caudal to injury }\end{array}$ & {$[154]$} \\
\hline
\end{tabular}

Abbreviations: $\mathrm{ECM}=$ extracellular matrix; PLGA = poly(co-lactic/glycolic acid); HA = hyaluronan; HAMC = hyaluronan and methylcellulose blend; TNF- $\alpha=$ tumor necrosis factor alpha; IL-6 = interleukin 6 ; NF- $\kappa \mathrm{B}=$ nuclear factor kappa-light-chain-enhancer of activated B cells; HSP-70 = heat shock protein 70; hMSC = human mesenchymal stem cell.

vascularized tissue [141]. The host responses to ECMbased materials have recently been reviewed [142].

\subsection{Materials to modulate the immune response}

Some materials are known to have innate antiinflammatory properties. A widely used material for spinal cord repair with anti-inflammatory effects is chitosan, a linear polysaccharide from the chitin shells of crustaceans [143]. The effects of chitosan on inflammation have been attributed to its ability to inhibit the secretion of TNF- $\alpha$ and IL-6 [144], increase the expression of heat shock protein 70 (HSP-70), and decrease the activation of NF- $\kappa \mathrm{B}$ resulting in antioxidative properties [145]. Chitosan was found to decrease neuro-inflammation and increase neuroprotection when implanted alone [146] or in combination with methylprednisolone [147] or cells [148]. Materials with direct or indirect immunomodulatory effects are listed in table 4.

\section{Surface micropatterning to impact inflammation and angiogenesis for spinal cord repair}

Materials communicate with cells through attachment and surface-membrane interactions. Thus, the micropattern of the surface of implanted materials can influence cells through directly initiating a signaling cascade or manipulating cell attachment and morphology. Modifications of the surface micro-pattern of materials allows regulation of material-cell interactions. The pattern on materials can be modified using photolithography [155] or soft lithography stamping techniques [156]. It was demonstrated that ECs and macrophages can be affected by changing the presentation of material surface markers. For instance, cells can be coaxed into an elongated morphology using cell adhesion ligands patterned in thin lines on the implanted material. Macrophages exposed to adhesion patterns could be shifted towards the M2-like phenotype with respect to both morphology and secretion profiles [157]. ECs can form microvessels along patterned surfaces [158]. Lithography techniques were used to direct and increase axon growth after SCI [159, 160]. Patterning of different ligands or combining and/or alternating patterns to simultaneously influence vasculature and immune cells could improve angiogenesis as well as axon regeneration and repair after SCI.

\section{Future directions}

A better understanding of vascular consequences and angiogenesis after different types, locations, and severities of SCIs could aid in the development of future therapies. SCIs are heterogeneous and each presents different requirements for angiogenesis and repair. Also, the progressive nature of SCIs stresses the notion that a strategy developed/tested in the environment of an acute injury may not be similarly effective for chronic injuries. Acutely, delivering angiogenic factors may elicit angiogenesis in the penumbra to establish new vasculature in the injury epicenter ('outside-in' approach). However, in time after SCI, more nervous tissue is lost, scar tissue has fully developed, and functioning vasculature is farther away from the injury epicenter. Thus, chronically, to realize new vasculature in the injury epicenter it may be necessary to introduce materials, with ECs and/or other supporting cells, combined with angiogenic factors ('inside-out' approach). A combinatorial intervention may provide the robust growth response demanded by the complexities of (especially) chronic SCI [81, 161]. The timing of delivery of angiogenic factors is a crucial consideration and should be accomplished with a high degree of temporal control to optimize immunomodulation and maximize functional revascularization of the damaged nervous tissue. One can imagine a counterproductive or even detrimental situation where factors that stabilize and fortify new vessels 
while inhibiting growth (i.e. PDGF and TGF- $\beta$ ) were presented at the injury site prior to introducing/ upregulating pro-vascular growth factors (i.e. VEGF and FGF). Likewise, having unregulated growth of immature and/or leaky vasculature could increase accessibility of the injury site to pro-inflammatory cells and cytokines, potentially increasing secondary tissue damage.

More and focused research on angiogenesis using systematic and quantifiable approaches is needed in the SCI field. Angiogenesis for spinal cord repair is relatively understudied and in its infancy. This is markedly different in other medical fields including cancer, rheumatoid arthritis, retinal disease, myocardial and peripheral ischemia, chronic wounds/lesions, where angiogenesis is a primary therapeutic target. Thus, there is much knowledge to be gained from the plethora of research on mechanisms underlying angiogenesis in these other disciplines. Mechanistic information may reveal novel therapeutic targets that can instruct the development of effective material-based strategies for revascularization of the damaged spinal cord.

In cancer research many therapies are being explored to halt the formation of new blood vessels. For instance, it was shown that blocking the $\alpha \mathrm{V} \beta 3$ integrin $[162,163]$ or its ligands inhibited blood vessel maturation which was accompanied by apoptosis of ECs [163]. A review on utilizing ECM for investigating tumor angiogenesis was recently published [164]. Reversely, for SCI, facilitating or overexpressing $\alpha \mathrm{V} \beta 3$ integrins, or introducing materials functionalized with its ligands, may enhance pro-angiogenic signaling and elicit the formation of new vasculature. In both cancer and retinal pathologies, treatments that block angiogenic factors, especially anti-VEGF, have been successfully developed and tested providing some promising results [165-168]. In cardiac and peripheral muscle ischemia and reperfusion injury, MSCs have been explored extensively for promoting angiogenesis and repair $[169,170]$.

Expansion of our potential therapeutic targets for angiogenesis may support the development of new therapies for SCI. For instance, there is a growing body of literature on neuron or glia-associated integrin activation for axon growth [171, 172] and cell survival [173]; however, the role of integrins in angiogenesis is understudied. Intensifying the research of integrins, and other so far understudied targets, in angiogenesis may reveal novel potential targets. In general, benefiting from the knowledge from other medical fields and exploring therapeutic targets from other aspects of spinal cord repair may help to develop effective angiogenesis-based therapies.

\section{Summary and conclusions}

Restoration of the damaged vascular network after SCI is a crucial step for maintenance and survival of damaged nervous tissue, axon regeneration, and long term functional recovery. The orchestra of inflammatory cells activated after injury in a sequentially regulated manner are involved in promoting angiogenesis and repair in the majority of tissues. However, this does not occur in the spinal cord which displays chronic inflammation in which M1-like macrophages maintain a hostile environment deprived of functional angiogenesis and tissue repair. Using biomaterials that directly or indirectly, through delivery of drugs or cells, affect repair through modulating the shift to M2like macrophages, promoting angiogenesis and/or vascular maturation, is a promising approach to mediate spinal cord repair. Research in adjacent fields may provide new therapeutic targets and support the design of new, more effective, repair approaches based on angiogenesis and/or immunomodulation. Additionally, more focused studies within the SCI field for elucidating the key mechanisms of SCI-associated angiogenesis and inflammation combined with collaborative efforts from engineers and material scientists could lead to the discovery and design of successful combinatorial strategies for repair of the injured spinal cord.

\section{Acknowledgments}

The authors would like to thank Megan Marlow for the artwork in figure 1. This work was supported by grants from the Wings for Life Foundation (WFL-US015/15), Morton Cure Paralysis Fund, Craig H Neilsen Foundation (284621), and The Department of Veteran Affairs (I01RX001807).

\section{References}

[1] Wolman L 1967 Blast injury of the spinal cord Paraplegia 5 83-8

[2] Means E D, Anderson D K, Nicolosi G and Gaudsmith J 1978 Microvascular perfusion experimental spinal cord injury Surg. Neurol. 9353-60

[3] Hagg T and Oudega M 2006 Degenerative and spontaneous regenerative processes after spinal cord injury J. Neurotrauma $23264-80$

[4] Oudega M 2010 Spinal cord injury and repair: role of blood vessel loss and endogenous angiogenesis $A d v$. Wound Care 1 335-40

[5] Fassbender J M, Whittemore S R and Hagg T 2011 Targeting microvasculature for neuroprotection after SCI Neurotherapeutics 8240-51

[6] Bramlett H M and Dietrich W D 2007 Progressive damage after brain and spinal cord injury: pathomechanisms and treatment strategies Prog. Brain Res. 161 125-41

[7] Ek C J et al 2010 Spatio-temporal progression of grey and white matter damage following contusion injury in rat spinal cord PLoS One 5 e 12021

[8] Li Y et al 2017 Pericytes impair capillary blood flow and motor function after chronic spinal cord injury Nat. Med. 23 733-41

[9] Xiong Y, Mahmood A and Chopp M 2010 Neurorestorative treatments for traumatic brain injury Discovery Med. 10 434-42

[10] Nag S, Kapadia A and Stewart D J 2011 Review: molecular pathogenesis of blood-brain barrier breakdown in acute brain injury Neuropathol. Appl. Neurobiol. 37 3-23 
[11] Reginato S, Gianni-Barrera R and Banfi A 2011 Taming of the wild vessel: promoting vessel stabilization for safe therapeutic angiogenesis Biochem. Soc. Trans. 39 1654-8

[12] Hassler O 1966 Blood supply to human spinal cord. A microangiographic study Arch. Neurol. $15302-7$

[13] Turnbull I M, Brieg A and Hassler O 1966 Blood supply of cervical spinal cord in man. A microangiographic cadaver study J. Neurosurg. 24 951-65

[14] Tator C H and Fehlings M G 1991 Review of the secondary injury theory of acute spinal cord trauma with emphasis on vascular mechanisms J. Neurosurg. 75 15-26

[15] Mautes A E, Weinzierl M R, Donovan F and Noble L J 2000 Vascular events after spinal cord injury: contribution to secondary pathogenesis Phys. Ther. 80 673-87

[16] Krassioukov A V, Furlan J C and Fehlings M G 2003 Autonomic dysreflexia in acute spinal cord injury: an underrecognized clinical entity J. Neurotrauma 20 707-16

[17] Whetstone W D, Hsu J Y, Eisenberg M, Werb Z and Noble-Haeusslein L J 2003 Blood-spinal cord barrier after spinal cord injury: relation to revascularization and wound healing J. Neurosci. Res. 74 227-39

[18] Casella G T, Bunge M B and Wood P M 2006 Endothelial cell loss is not a major cause of neuronal and glial cell death following contusion injury of the spinal cord Exp. Neurol. 202 $8-20$

[19] Benton R L, Maddie M A, Minnillo D R, Hagg T and Whittemore S 2008 Griffonia simplicifolia isolectin B4 identifies a specific subpopulation of angiogenic blood vessels following contusive spinal cord injury in the adult mouse J. Comparative Neurol. 507 1031-52

[20] Hall E D and Braughler J M 1986 Role of lipid peroxidation in post-traumatic spinal cord degeneration: a review Cent Nervous Syst. Trauma $3281-94$

[21] Hynes R O 1992 Integrins: versatility, modulation, and signaling in cell adhesion Cell 69 11-25

[22] Popovich P G 2000 Immunological regulation of neuronal degeneration and regeneration in the injured spinal cord Prog. Brain Res. 128 43-58

[23] Carmeliet P 2005 Angiogenesis in life, disease and medicine Nature 438 932-6

[24] Matsumoto M et al 1999 The effects of NG-nitro-L-argininemethyl ester on neurologic and histopathologic outcome after transient spinal cord ischemia in rabbits Anesthesia Analgesia 89 696-702

[25] Guizar-Sahagun G et al 2004 Systemic microcirculation after complete high and low thoracic spinal cord section in rats J. Neurotrauma 21 1614-23

[26] Zhang Q et al 2010 Circulating mitochondrial DAMPs cause inflammatory responses to injury Nature 464 104-7

[27] Zhang X and Mosser D M 2008 Macrophage activation by endogenous danger signals J. Pathol. 214 161-78

[28] Tator C H 1995 Update on the pathophysiology and pathology of acute spinal cord injury Brain Pathol. 5 407-13

[29] Donnelly D J and Popovich P G 2008 Inflammation and its role in neuroprotection, axonal regeneration and functional recovery after spinal cord injury Exp. Neurol. 209 378-88

[30] McTigue D M et al 1998 Selective chemokine mRNA accumulation in the rat spinal cord after contusion injury J. Neurosci. Res. 53 368-76

[31] Ma M, Wei T, Boring L, Charo I F, Ransohoff R M and Jakeman L B 2002 Monocyte recruitment and myelin removal are delayed following spinal cord injury in mice with CCR2 chemokine receptor deletion J. Neurosci. Res. 68 691-702

[32] Owen J L and Mohamadzadeh M 2013 Macrophages and chemokines as mediators of angiogenesis Frontiers Physiol. 4159

[33] Popovich P G, Guan Z, McGaughy V, Fisher L, Hickey W F and Basso D M 2002 The neuropathological and behavioral consequences of intraspinal microglial/ macrophage activation J. Neuropathol. Exp. Neurol. 61 623-33

[34] Li J et al 2017 Effect of VEGF on inflammatory regulation, neural survival, and functional improvement in rats following a complete spinal cord transection Frontiers Cell. Neurosci. 11381

[35] Kigerl K A, Gensel J C, Ankeny D P, Alexander J K, Donnelly D J and Popovich P G 2009 Identification of two distinct macrophage subsets with divergent effects causing either neurotoxicity or regeneration in the injured mouse spinal cord J. Neurosci. 29 13435-44

[36] Gensel J C and Zhang B 2015 Macrophage activation and its role in repair and pathology after spinal cord injury Brain Res. $16191-11$

[37] Fleming J C et al 2006 The cellular inflammatory response in human spinal cords after injury Brain 1293249-69

[38] Lentsch A B and Ward P A 2000 Regulation of inflammatory vascular damage J. Pathol. $190343-8$

[39] Nucera S, Biziato D and De Palma M 2011 The interplay between macrophages and angiogenesis in development, tissue injury and regeneration Int. J. Dev. Biol. 55 495-503

[40] Fantin A et al 2010 Tissue macrophages act as cellular chaperones for vascular anastomosis downstream of VEGFmediated endothelial tip cell induction Blood 116 829-40

[41] Okuno Y, Nakamura-Ishizu A, Kishi K, Suda T and Kubota Y 2011 Bone marrow-derived cells serve as proangiogenic macrophages but not endothelial cells in wound healing Blood 117 5264-72

[42] Medzhitov R 2008 Origin and physiological roles of inflammation Nature 454 428-35

[43] Casella G T, Marcillo A, Bunge M B and Wood P M 2002 New vascular tissue rapidly replaces neural parenchyma and vessels destroyed by a contusion injury to the rat spinal cord Exp. Neurol. $17363-76$

[44] Loy D N, Crawford C H, Darnall J B, Burke D A, Onifer S M and Whittemore S R 2002 Temporal progression of angiogenesis and basal lamina deposition after contusive spinal cord injury in the adult rat J. Comparative Neurol. 445 308-24

[45] Longbrake E E, Lai W, Ankeny D P and Popovich P G 2007 Characterization and modeling of monocyte-derived macrophages after spinal cord injury J. Neurochem. 102 1083-94

[46] Wang Get al 2013 Microglia/macrophage polarization dynamics in white matter after traumatic brain injury J. Cerebral Blood Flow Metab. 33 1864-74

[47] Velardo M J et al 2004 Patterns of gene expression reveal a temporally orchestrated wound healing response in the injured spinal cord J. Neurosci. 24 8562-76

[48] Corliss B A, Azimi M S, Munson J M, Peirce S M and Murfee W L 2016 Macrophages: an inflammatory link between angiogenesis and lymphangiogenesis Microcirculation 23 95-121

[49] Pollard J W 2009 Trophic macrophages in development and disease Nat. Rev. Immunol. 9 259-70

[50] Spiller K L and Koh T J 2017 Macrophage-based therapeutic strategies in regenerative medicine Adv. Drug Deliv. Rev. 122 74-83

[51] Sunderkotter C, Steinbrink K, Goebeler M, Bhardwaj R and Sorg C 1994 Macrophages and angiogenesis J. Leukocyte Biol. 55 410-22

[52] Zhang X, Goncalves R and Mosser D M 2008 The isolation and characterization of murine macrophages Curr. Protocols Immunol. 83 14.1.1-14

[53] Anderson C F and Mosser D M 2002 A novel phenotype for an activated macrophage: the type 2 activated macrophage J. Leukocyte Biol. 72 101-6

[54] Gordon S 2003 Alternative activation of macrophages Nat. Rev. Immunol. 323-35

[55] Ardi V C, Kupriyanova T A, Deryugina E I and Quigley J P 2007 Human neutrophils uniquely release TIMP-free MMP9 to provide a potent catalytic stimulator of angiogenesis Proc. Natl Acad. Sci. USA $10420262-7$

[56] Spiller K L et al 2015 Sequential delivery of immunomodulatory cytokines to facilitate the M1-to-M2 transition of macrophages and enhance vascularization of bone scaffolds Biomaterials 37 194-207 
[57] Miron V E et al 2013 M2 microglia and macrophages drive oligodendrocyte differentiation during CNS remyelination Nat. Neurosci. $161211-8$

[58] Potente M, Gerhardt H and Carmeliet P 2011 Basic and therapeutic aspects of angiogenesis Cell 146 873-87

[59] Wynn T A and Vannella K M 2016 Macrophages in tissue repair, regeneration, and fibrosis Immunity 44 450-62

[60] Lucas T et al 2010 Differential roles of macrophages in diverse phases of skin repair J. Immunol. 1843964-77

[61] Lutton C, Young Y W, Williams R, Meedeniya A C, Mackay-Sim A and Goss B 2012 Combined VEGF and PDGF treatment reduces secondary degeneration after spinal cord injury J. Neurotrauma 29 957-70

[62] Zajac E et al 2013 Angiogenic capacity of M1- and M2polarized macrophages is determined by the levels of TIMP-1 complexed with their secreted proMMP-9 Blood 122 4054-67

[63] Spiller K L et al 2014 The role of macrophage phenotype in vascularization of tissue engineering scaffolds Biomaterials 35 4477-88

[64] Kodelja V, Muller C, Tenorio S, Schebesch C, Orfanos C E and Goerdt S 1997 Differences in angiogenic potential of classically versus alternatively activated macrophages Immunobiology 197 478-93

[65] Klagsbrun M and Moses M A 1999 Molecular angiogenesis Chem. Biol. 6 R217-24

[66] Herrmann M, Verrier S and Alini M 2015 Strategies to stimulate mobilization and homing of endogenous stem and progenitor cells for bone tissue repair Frontiers Bioeng. Biotechnol. 379

[67] Kitamura Ket al 2007 Hepatocyte growth factor promotes endogenous repair and functional recovery after spinal cord injury J. Neurosci. Res. 85 2332-42

[68] Loy D N, Crawford C H, Darnall J B, Burke D A, Onifer S M and Whittemore S 2002 Temporal progression of angiogenesis and basal lamina deposition after contusive spinal cord injury in the adult rat J. Comparative Neurol. 445 308-24

[69] Oudega M 2012 Molecular and cellular mechanisms underlying the role of blood vessels in spinal cord injury and repair Cell Tissue Res. 349 269-88

[70] Ritfeld G J et al 2015 The role of brain-derived neurotrophic factor in bone marrow stromal cell-mediated spinal cord repair Cell Transplant. 242209-20

[71] Xie N et al 2016 Transplantation of placenta-derived mesenchymal stem cells enhances angiogenesis after ischemic limb injury in mice J. Cell. Mol. Med. 20 29-37

[72] Ritfeld G J et al 2012 Bone marrow stromal cell-mediated tissue sparing enhances functional repair after spinal cord contusion in adult rats Cell Transplant. 21 1561-75

[73] Hejčl A et al 2010 HPMA-RGD hydrogels seeded with mesenchymal stem cells improve functional outcome in chronic spinal cord injury Stem Cells Dev. 19 1535-46

[74] Liekens S, De Clercq E and Neyts J 2001 Angiogenesis: regulators and clinical applications Biochem. Pharmacol. 61 253-70

[75] Varner J A, Brooks P C and Cheresh D A 1995 Review: the integrin $\alpha_{\mathrm{v}} \beta_{3}$ : angiogenesis and apoptosis Cell Adhes. Commun. 3367-74

[76] Belair D G, Le N N and Murphy W L 2014 Design of growth factor sequestering biomaterials Chem. Commun. 50 15651-68

[77] Davis G E and Senger D R 2005 Endothelial extracellular matrix: biosynthesis, remodeling, and functions during vascular morphogenesis and neovessel stabilization Circ. Res. 97 1093-107

[78] West D C, Hampson I N, Arnold F and Kumar S 1985 Angiogenesis induced by degradation products of hyaluronic acid Science 228 1324-6

[79] Arulmoli J et al 2016 Combination scaffolds of salmon fibrin, hyaluronic acid, and laminin for human neural stem cell and vascular tissue engineering Acta Biomater. 43 122-38

[80] Wei Y T et al 2010 Hyaluronic acid hydrogel modified with nogo-66 receptor antibody and poly-L-lysine to promote axon regrowth after spinal cord injury J. Biomed. Mater. Res. B $95110-7$

[81] Xue L and Greisler H P 2002 Angiogenic effect of fibroblast growth factor- 1 and vascular endothelial growth factor and their synergism in a novel in vitro quantitative fibrin-based three-dimensional angiogenesis system Surgery 132 259-67

[82] Kroon M E, van Schie M L, van der Vecht B, van Hinsbergh V W and Koolwijk P 2002 Collagen type 1 retards tube formation by human microvascular endothelial cells in a fibrin matrix Angiogenesis 5 257-65

[83] Baier Leach J, Bivens K A, Patrick C W Jr and Schmidt C E 2003 Photocrosslinked hyaluronic acid hydrogels: natural, biodegradable tissue engineering scaffolds Biotechnol. Bioeng. $82578-89$

[84] Collier J H, Camp J P, Hudson T W and Schmidt C E 2000 Synthesis and characterization of polypyrrole-hyaluronic acid composite biomaterials for tissue engineering applications J. Biomed. Mater. Res. 50 574-84

[85] Wang L, Shi Q, Dai J, Gu Y, Feng Y and Chen L 2017 Increased vascularization promotes functional recovery in the transected spinal cord rats by implanted vascular endothelial growth factor-targeting collagen scaffold J. Orthopaedic Res. 36 1024-34

[86] Badylak S F 2002 The extracellular matrix as a scaffold for tissue reconstruction Semin. Cell Dev. Biol. 13 377-83

[87] Gilbert T W, Stolz D B, Biancaniello F, Simmons-Byrd A and Badylak S F 2005 Production and characterization of ECM powder: implications for tissue engineering applications Biomaterials 26 1431-5

[88] Medberry C Jet al 2013 Hydrogels derived from central nervous system extracellular matrix Biomaterials 34 1033-40

[89] Tukmachev D et al 2016 Injectable extracellular matrix hydrogels as scaffolds for spinal cord injury repair Tissue Eng. A 22 306-17

[90] Li C et al 2012 Allografts of the acellular sciatic nerve and brain-derived neurotrophic factor repair spinal cord injury in adult rats PLoS One 7 e 42813

[91] Rubin P A, Nicaeus T E, Warner M A and Remulla H D 1997 Effect of sucralfate and basic fibroblast growth factor on fibrovascular ingrowth into hydroxyapatite and porous polyethylene alloplastic implants using a novel rabbit model Ophthalmic Plast. Reconstruct. Surg. 13 8-17

[92] Yu J, Gu Y, Du K T, Mihardja S, Sievers R E and Lee R J 2009 The effect of injected RGD modified alginate on angiogenesis and left ventricular function in a chronic rat infarct model Biomaterials 30 751-6

[93] Haggerty A E and Oudega M 2013 Biomaterials for spinal cord repair Neurosci. Bull. 29 445-59

[94] Bakshi A, Fisher O, Dagci T, Himes B T, Fischer I and Lowman A 2004 Mechanically engineered hydrogel scaffolds for axonal growth and angiogenesis after transplantation in spinal cord injury J. Neurosurg. Spine 1322-9

[95] Atzet S, Curtin S, Trinh P, Bryant S and Ratner B 2008 Degradable poly(2-hydroxyethyl methacrylate)-copolycaprolactone hydrogels for tissue engineering scaffolds Biomacromolecules 93370-7

[96] Zhang L, Zheng G J, Guo Y T, Zhou L, Du J and He H 2014 Preparation of novel biodegradable pHEMA hydrogel for a tissue engineering scaffold by microwave-assisted polymerization Asian Pac. J. Tropical Med. 7 136-40

[97] Zhang Y, Chu D F, Zheng M Y, Kissel T and Agarwal S 2012 Biocompatible and degradable poly(2-hydroxyethyl methacrylate) based polymers for biomedical applications Polym. Chem. 3 2752-9

[98] Park D, Wu W and Wang Y 2011 A functionalizable reverse thermal gel based on a polyurethane/PEG block copolymer Biomaterials 32 777-86

[99] Ritfeld G J et al 2014 The effect of a polyurethane-based reverse thermal gel on bone marrow stromal cell transplant survival and spinal cord repair Biomaterials 35 1924-31

[100] Hsieh F Y, Lin H H and Hsu S H 2015 3D bioprinting of neural stem cell-laden thermoresponsive biodegradable 
polyurethane hydrogel and potential in central nervous system repair Biomaterials 71 48-57

[101] Doi K and Matsuda T 1997 Enhanced vascularization in a microporous polyurethane graft impregnated with basic fibroblast growth factor and heparin J. Biomed. Mater. Res. 34 361-70

[102] Johnson P J, Parker S R and Sakiyama-Elbert S E 2010 Fibrinbased tissue engineering scaffolds enhance neural fiber sprouting and delay the accumulation of reactive astrocytes at the lesion in a subacute model of spinal cord injury J. Biomed. Mater. Res. A 92 152-63

[103] Novikova L N, Novikov L N and Kellerth J O 2003 Biopolymers and biodegradable smart implants for tissue regeneration after spinal cord injury Curr. Opin. Neurol. 16 $711-5$

[104] Tsai E C, Dalton P D, Shoichet M S and Tator C H 2006 Matrix inclusion within synthetic hydrogel guidance channels improves specific supraspinal and local axonal regeneration after complete spinal cord transection Biomaterials 27 519-33

[105] Gonzalez-Perez F et al 2016 Substratum preferences of motor and sensory neurons in postnatal and adult rats Eur. J. Neurosci. 43 431-42

[106] Haggerty A E, Marlow M M and Oudega M 2016 Extracellular matrix components as therapeutics for spinal cord injury Neurosci. Lett. 652 50-5

[107] Lin C Y, Lee Y S, Lin V W and Silver J 2012 Fibronectin inhibits chronic pain development after spinal cord injury J. Neurotrauma 29 589-99

[108] Whitworth I H, Brown R A, Dore C J, Anand P, Green C J and Terenghi G 1996 Nerve growth factor enhances nerve regeneration through fibronectin grafts J. Hand Surg. Br. 21 514-22

[109] Bignami A, Hosley M and Dahl D 1993 Hyaluronic acid and hyaluronic acid-binding proteins in brain extracellular matrix Anat. Embryol. 188 419-33

[110] Jiang D, Liang J and Noble P W 2007 Hyaluronan in tissue injury and repair Annu. Rev. Cell Dev. Biol. 23 435-61

[111] Zin Z K, Brian D M, Jennifer E V, Stephanie K S, Raymond J G and Christine E S 2011 High molecular weight hyaluronic acid limits astrocyte activation and scar formation after spinal cord injury J. Neural Eng. 8046033

[112] Cholas R H, Hsu H P and Spector M 2012 The reparative response to cross-linked collagen-based scaffolds in a rat spinal cord gap model Biomaterials 33 2050-9

[113] Estrada V et al 2014 Long-lasting significant functional improvement in chronic severe spinal cord injury following scar resection and polyethylene glycol implantation Neurobiol. Dis. 67 165-79

[114] Park K I, Teng Y D and Snyder E Y 2002 The injured brain interacts reciprocally with neural stem cells supported by scaffolds to reconstitute lost tissue Nat. Biotechnol. $201111-7$

[115] Rauch M F et al 2009 Engineering angiogenesis following spinal cord injury: a coculture of neural progenitor and endothelial cells in a degradable polymer implant leads to an increase in vessel density and formation of the blood-spinal cord barrier Eur. J. Neurosci. 29 132-45

[116] Maquet $V$ et al 2001 Poly(D,L-lactide) foams modified by poly (ethylene oxide)-block-poly(D,L-lactide) copolymers and a-FGF: in vitro and in vivo evaluation for spinal cord regeneration Biomaterials 22 1137-46

[117] Kang C E, Baumann M D, Tator C H and Shoichet M S 2013 Localized and sustained delivery of fibroblast growth factor-2 from a nanoparticle-hydrogel composite for treatment of spinal cord injury Cells Tissues Organs 197 55-63

[118] Wen Y et al 2016 Spinal cord injury repair by implantation of structured hyaluronic acid scaffold with PLGA microspheres in the rat Cell Tissue Res. 364 17-28

[119] Xu Z X et al 2017 Acellular spinal cord scaffold implantation promotes vascular remodeling with sustained delivery of VEGF in a rat spinal cord hemisection model Curr. Neurovascular Res. 14 274-89
[120] Yu S, Yao S, Wen Y, Wang Y, Wang H and Xu Q 2016 Angiogenic microspheres promote neural regeneration and motor function recovery after spinal cord injury in rats Sci. Rep. 633428

[121] Zhao Q et al 2015 Polylactic-co-glycolic acid microspheres containing three neurotrophic factors promote sciatic nerve repair after injury Neural. Regener. Res. 10 1491-7

[122] Patist C M, Mulder M B, Gautier S E, Maquet V, Jerome R and Oudega M 2004 Freeze-dried poly(D,L-lactic acid) macroporous guidance scaffolds impregnated with brainderived neurotrophic factor in the transected adult rat thoracic spinal cord Biomaterials 25 1569-82

[123] Berry M et al 2001 Sustained effects of gene-activated matrices after CNS injury Mol. Cell. Neurosci. 17 706-16

[124] Kyriakides T R, Hartzel T, Huynh G and Bornstein P 2001 Regulation of angiogenesis and matrix remodeling by localized, matrix-mediated antisense gene delivery Mol. Ther. 3 842-9

[125] Lee KY, Peters M C and mooney D J 2003 Comparison of vascular endothelial growth factor and basic fibroblast growth factor on angiogenesis in SCID mice J. Control. Release 87 49-56

[126] Des Rieux A et al 2014 Vascular endothelial growth factorloaded injectable hydrogel enhances plasticity in the injured spinal cord J. Biomed. Mater. Res. A 102 2345-55

[127] Tanihara M, Suzuki Y, Yamamoto E, Noguchi A and Mizushima Y 2001 Sustained release of basic fibroblast growth factor and angiogenesis in a novel covalently crosslinked gel of heparin and alginate J. Biomed. Mater. Res. 56216-21

[128] Kang C E, Tator C H and Shoichet M S 2010 Poly(ethylene glycol) modification enhances penetration of fibroblast growth factor 2 to injured spinal cord tissue from an intrathecal delivery system J. Control. Release 144 25-31

[129] Quertainmont R, Cantinieaux D, Botman O, Sid S, Schoenen J and Franzen R 2012 Mesenchymal stem cell graft improves recovery after spinal cord injury in adult rats through neurotrophic and pro-angiogenic actions PLoS One 7 e39500

[130] Huang J-H et al 2017 Systemic administration of exosomes released from mesenchymal stromal cells attenuates apoptosis, inflammation, and promotes angiogenesis after spinal cord injury in rats J. Neurotrauma 34 3388-96

[131] Frerich B, Lindemann N, Kurtz-Hoffmann J and Oertel K 2001 In vitro model of a vascular stroma for the engineering of vascularized tissues Int. J. Oral Maxillofacial Surg. 30 414-20

[132] Hurtado A, Moon L D, Maquet V, Blits B, Jerome R and Oudega M 2006 Poly (D,L-lactic acid) macroporous guidance scaffolds seeded with Schwann cells genetically modified to secrete a bi-functional neurotrophin implanted in the completely transected adult rat thoracic spinal cord Biomaterials 27 430-42

[133] Itosaka $\mathrm{H}$ et al 2009 Fibrin matrix provides a suitable scaffold for bone marrow stromal cells transplanted into injured spinal cord: a novel material for CNS tissue engineering Neuropathology 29248-57

[134] Hudon V, Berthod F, Black A F, Damour O, Germain L and Auger F A 2003 A tissue-engineered endothelialized dermis to study the modulation of angiogenic and angiostatic molecules on capillary-like tube formation in vitro Br. J. Dermatol. 148 1094-104

[135] Zeng X et al 2011 Bone marrow mesenchymal stem cells in a three-dimensional gelatin sponge scaffold attenuate inflammation, promote angiogenesis, and reduce cavity formation in experimental spinal cord injury Cell Transplant. 20 1881-99

[136] Tonello C, Zavan B, Cortivo R, Brun P, Panfilo S and Abatangelo G 2003 In vitro reconstruction of human dermal equivalent enriched with endothelial cells Biomaterials 24 1205-11

[137] McWhorter F Y, Davis C T and Liu W F 2015 Physical and mechanical regulation of macrophage phenotype and function Cell. Mol. Life Sci. 72 1303-16 
[138] Blakney A K, Swartzlander M D and Bryant S J 2012 The effects of substrate stiffness on the in vitro activation of macrophages and in vivo host response to poly(ethylene glycol)-based hydrogels J. Biomed. Mater. Res. A 100 1375-86

[139] Kligman A M and Armstrong R C 1986 Histologic response to intradermal Zyderm and Zyplast (glutaraldehyde crosslinked) collagen in humans J. Dermatol. Surg. Oncol. 12 351-7

[140] Peng Zet al 2016 Promotion of neurological recovery in rat spinal cord injury by mesenchymal stem cells loaded on nerve-guided collagen scaffold through increasing alternatively activated macrophage polarization J. Tissue Eng. Regen. Med. 12 e1725-36

[141] Brown B N, Valentin J E, Stewart-Akers A M, McCabe G P and Badylak S F 2009 Macrophage phenotype and remodeling outcomes in response to biologic scaffolds with and without a cellular component Biomaterials 30 1482-91

[142] Morris A H, Stamer D K and Kyriakides T R 2017 The host response to naturally-derived extracellular matrix biomaterials Semin. Immunol. 29 79-91

[143] White S A, Farina P R and Fulton I 1979 Production and isolation of chitosan from Mucor rouxii Appl. Environ. Microbiol. 38 323-8

[144] Kim M S, Sung M J, Seo S B, Yoo S J, Lim W K and Kim H M 2002 Water-soluble chitosan inhibits the production of proinflammatory cytokine in human astrocytoma cells activated by amyloid beta peptide and interieukin-1 beta Neurosci. Lett. 321 105-9

[145] Khodagholi F, Eftekharzadeh B, Maghsoudi N and Rezaei P F 2010 Chitosan prevents oxidative stress-induced amyloid beta formation and cytotoxicity in NT2 neurons: involvement of transcription factors Nrf2 and NF-kappa B Mol. Cell. Biochem. 337 39-51

[146] Chedly J et al 2017 Physical chitosan microhydrogels as scaffolds for spinal cord injury restoration and axon regeneration Biomaterials 138 91-107

[147] Bin S, Zhou N F, Pan J, Pan F M, Wu X F and Zhou Z H 2017 Nano-carrier mediated co-delivery of methyl prednisolone and minocycline for improved post-traumatic spinal cord injury conditions in rats Drug Dev. Ind. Pharm. 43 1033-41

[148] Zhu L, Liu T, Cai J, Ma J and Chen A M 2015 Repair and regeneration of lumbosacral nerve defects in rats with chitosan conduits containing bone marrow mesenchymal stem cells Injury $462156-63$

[149] Wolf M T et al 2014 Macrophage polarization in response to ECM coated polypropylene mesh Biomaterials 35 6838-49

[150] Menezes K, Lacerda de Menezes J, Nascimento M, de Siqueira Santos R and Coelho-Sampaio T 2010 Polylaminin, a polymeric form of laminin, promotes regeneration after spinal cord injury FASEB J. 24 4513-22

[151] Ropper A E et al 2017 Defining recovery neurobiology of injured spinal cord by synthetic matrix-assisted hMSC implantation Proc. Natl Acad. Sci. USA 114 E820-9

[152] Rayahin JE, Buhrman J S, Zhang Y, Koh T J and Gemeinhart R A 2015 High and low molecular weight hyaluronic acid differentially influence macrophage activation ACS Biomater. Sci. Eng. 1 481-93

[153] Austin J W, Gilchrist C and Fehlings M G 2012 High molecular weight hyaluronan reduces lipopolysaccharide mediated microglial activation J. Neurochem. 122 344-55

[154] Austin J W et al 2012 The effects of intrathecal injection of a hyaluronan-based hydrogel on inflammation, scarring and neurobehavioural outcomes in a rat model of severe spina cord injury associated with arachnoiditis Biomaterials 33 4555-64

[155] Kersten P, Bouwstra S and Petersen J W 1995 Photolithography on micromachined 3D surfaces using electrodeposited photoresists Sensors Actuators A 51 51-4

[156] Xia Y N and Whitesides G M 1998 Soft lithography Angew. Chem., Int. Ed. Engl. 37 550-75

[157] McWhorter F Y, Wang T, Nguyen P, Chung T and Liu W F 2013 Modulation of macrophage phenotype by cell shape Proc. Natl Acad. Sci. USA 110 17253-8

[158] Moldovan N I and Ferrari M 2002 Prospects for microtechnology and nanotechnology in bioengineering of replacement microvessels Arch. Pathol. Lab. Med. 126 320-4

[159] Zhang X, Prasad S, Niyogi S, Morgan A, Ozkan M and Ozkan C S 2005 Guided neurite growth on patterned carbon nanotubes Sensors Actuators B 106 843-50

[160] Wang D Y and Huang Y Y 2008 Fabricate coaxial stacked nerve conduits through soft lithography and molding processes J. Biomed. Mater. Res. A 85A 434-8

[161] Xue H, Zhang XY, Liu J M, Song Y, Li Y F and Chen D 2013 Development of a chemically extracted acellular muscle scaffold seeded with amniotic epithelial cells to promote spinal cord repair J. Biomed. Mater. Res. A 101 145-56

[162] Brooks P C, Clark R A and Cheresh D A 1994 Requirement of vascular integrin alpha v beta 3 for angiogenesis Science 264 569-71

[163] Brooks P C et al 1994 Integrin alpha v beta 3 antagonists promote tumor regression by inducing apoptosis of angiogenic blood vessels Cell 79 1157-64

[164] Hielscher A C and Gerecht S 2012 Engineering approaches for investigating tumor angiogenesis: exploiting the role of the extracellular matrix Cancer Res. 72 6089-96

[165] Ferrara N and Adamis A P 2016 Ten years of anti-vascular endothelial growth factor therapy Nat. Rev. Drug Discovery 15 385-403

[166] Ferrara N and Alitalo K 1999 Clinical applications of angiogenic growth factors and their inhibitors Nat. Med. 5 1359-64

[167] Tcheng JE et al 1994 Pharmacodynamics of chimeric glycoprotein IIb/IIIa integrin antiplatelet antibody Fab 7E3 in high-risk coronary angioplasty Circulation 90 1757-64

[168] Topol E J et al 1994 Randomised trial of coronary intervention with antibody against platelet IIb/IIIa integrin for reduction of clinical restenosis: results at six months. The EPIC Investigators Lancet 343 881-6

[169] Rowart P et al 2015 Mesenchymal stromal cell therapy in ischemia/reperfusion injury J. Immunol. Res. 2015602597

[170] Hua P, Liu J Y, Tao J and Yang S R 2015 Application and progress of combined mesenchymal stem cell transplantation in the treatment of ischemic cardiomyopathy Biomed. Res. Int. 2015568502

[171] Tan C L, Kwok J C, Patani R, Ffrench-Constant C, Chandran S and Fawcett J W 2011 Integrin activation promotes axon growth on inhibitory chondroitin sulfate proteoglycans by enhancing integrin signaling J. Neurosci. 31 6289-95

[172] Cheah M et al 2016 Expression of an activated integrin promotes long-distance sensory axon regeneration in the spinal cord J. Neurosci. 36 7283-97

[173] Stupack D G and Cheresh D A 2002 Get a ligand, get a life: integrins, signaling and cell survival J. Cell Sci. 115 3729-38 